\title{
ESTUDO EXPLORATÓRIO COMPARATIVO DA EFICÁCIA ENTRE PROTÓTIPOS FÍSICO, ANALÍTICO 2D E 3D NA IDENTIFICAÇÃO DE INCONSISTÊNCIAS DE PROJETOS
}

\author{
A comparative exploratory study on the \\ effectiveness of physical, analytical 2D and \\ 3D prototypes for the identification of design \\ inconsistencies
}

\author{
Lucas Melchiori Pereira', Fernanda Aranha Saffaro', Ercilia Hitomi Hirota', \\ Celso Saito'
}

RESUMO O protótipo é um recurso valioso ao processo de desenvolvimento de um produto (PDP), pois permite melhorar tanto o conhecimento e o desempenho do produto como a confiabilidade acerca do produto e dos processos relacionados a seu desenvolvimento e produção. Particularmente na indústria do ambiente construído, o desenvolvimento de protótipos físicos apresenta algumas restrições inerentes ao caráter único de seu produto. Entende-se que a prototipagem física de apartamentos-tipo, atualmente utilizada para resolução de inconsistências de projeto, pode ser aproveitada com mais eficácia na melhoria dos processos produtivos em canteiro de obra desde que aquelas inconsistências, que são o foco atual, sejam mitigadas com a incorporação da prototipagem virtual ao PDP do ambiente construído. Esta incoporação é atualmente viável a partir de ferramentas BIM. O objetivo deste artigo é discutir a capacidade das prototipagens física focada, analítica 3D e 2D para identificar inconsistências nos projetos executivos, com base nos resultados obtidos em um estudo exploratório que confronta o desempenho desses protótipos. Neste estudo, foram compostas equipes distintas para o desenvolvimento das 3 tipologias de protótipos e foram definidos critérios para avaliação da eficácia dos mesmos na detecção de inconsistências. Os resultados apontam os benefícios da modelagem BIM em termos de eficácia, custos e prazo.

PALAVRAS-CHAVE: Prototipagem, Modelagem paramétrica, Integração de projeto.

ABSTRACT Prototype is a valuable resource to the product development process (PDP) because it allows improvements on both knowledge about and performance of the product, as well as the reliability on the product and processes related to its development and production processes. Particularly in the built environment industry, the development of physical prototypes has some inherent restrictions due to the uniqueness of its product. It is understood that physical prototyping focused on the typical unit from residential projects, currently used for solving design conflicts, can be more effective for improving production processes in the construction site since those inconsistencies, which are the current focus, are mitigated by the incorporation of virtual prototyping to the PDP of the constructed environment. This practice is currently feasible due to the availability of tools that enable BIM. The objective of this paper is to discuss the capability of focused physical, virtual analytical and analytical representative prototypes for the identification of design inconsistencies. This discussion is based on the results of an exploratory study, developed in a building company, for which three different teams tackled the three different prototypes. Some criteria for effectiveness assessment were also defined. The results show the benefits from BIM in terms of effectiveness, costs and time.

KEYWORDS: Prototyping, Parametric modeling, Design integration.

\section{How to cite this article:}

PEREIRA, L. M.; SAFFARO, F. A.; HIROTA, E. H.; SAITO, C. Estudo exploratório comparativo da eficácia entre protótipos físico, analítico 2D e 3D na identificação de inconsistências de projetos Gestão e Tecnologia de Projetos, São Paulo, v. 10, n. 1, p. 29-47, jan./jun. 2015

http://dx.doi.org/10.11606/gtp.v10i1.83373
Fonte de financiamento: Declaram não haver. Conflito de interesse: Declaram não haver. Submetido em: 05 mar. 2015 Aceito em: 06 maio 2015 


\section{INTRODUÇÃO}

A necessidade da indústria do ambiente construído no desenvolvimento de soluções que confiram a qualidade esperada e custo menor a seu produto, associado à agilidade da produção, implica uma busca por tecnologias voltadas a melhorar o processo de desenvolvimento do produto. $\mathrm{O}$ emprego de protótipos é um meio largamente explorado na indústria de manufatura para esse fim, uma vez que promove agilidade na troca de conhecimento, permite avaliar o desempenho frente às expectativas e, consequentemente, aumenta a confiabilidade dos processos relacionados ao desenvolvimento do produto.

Porém, as dificuldades inerentes ao uso de protótipos para o desenvolvimento de um produto único têm restringido sua adoção como um meio de diminuir os riscos envolvidos no processo de desenvolvimento do produto (PDP). Além disso, o emprego da prototipagem é comumente reduzido na indústria do ambiente construído (IAC), sendo associado, principalmente, à construção de parte da edificação para vendas ou compatibilização, ignorando as diversas possibilidades exploradas em outros setores industriais.

\section{OBJETIVO DO ARTIGO}

Menos flexível que os protótipos analíticos nas alterações ao longo do processo de desenvolvimento do produto (PDP), a prototipagem física é um recurso capaz de representar e detectar fenômenos difíceis de serem avaliados em modelos intangíveis, como é o caso daqueles produzidos com a prototipagem analítica. Diversos autores, entre eles, Rosenthal e Tatikonda (1992), Brown e Eisenhardt (1995), Reinertsen (1997), Patterson (1999), Holmberg (2000), Faithfull, Ball e Jones (2001) e Ulrich e Eppinger (2011) sugerem o uso precoce e concatenado dos recursos de prototipagem analítica e física ao longo das etapas de desenvolvimento do produto.

Existem casos de emprego de protótipos físicos na construção civil, especialmente em show rooms (apartamentos modelos), com a finalidade de alavancar vendas nas etapas iniciais dos empreendimentos e no próprio canteiro de obras com o intuito de resolver problemas não identificados na etapa de projeto. No entanto, não há, na literatura, a apresentação de estudos científicos explorando os benefícios advindos do uso concatenado da prototipagem análitica e física. Escassos também são os trabalhos publicados que visam a estabelecer um correto dimensionamento dos ganhos, das perdas e dos custos reais advindos do emprego de protótipos, sejam eles analíticos ou físicos.

Este artigo apresenta os resultados de um estudo desenvolvido sob essa perspectiva, em que se compara a capacidade das prototipagens física focada, analítica 3D e 2D para identificar inconsistências nos projetos executivos liberados para uma obra real. Ao final, são apresentados os custos adicionais relativos a retrabalhos na etapa de produção que poderiam ser evitados com a construção de modelos virtuais. Com isso, pretende-se contribuir para o aprofundamento do debate sobre a implementação de práticas de prototipagem analítica e física no desenvolvimento do edifício, fornecendo elementos objetivos e consistentes acerca do desempenho de protótipos físicos e analíticos na resolução de inconsistências de projeto.

\section{CONCEITOS DE PROTOTIPAGEM}

Ulrich e Eppinger (2011) descrevem conceitualmente o protótipo como uma aproximação do produto ou de parte deste. Ou seja, a reprodução experimental de uma parte ou de um aspecto do produto que seja o objeto de 
interesse da equipe de projetistas já pode ser entendido como um protótipo. Esses autores acrescentam que podem ser empregadas formas diversas de representação, desde esboços, modelos matemáticos até a pré-produção completa do produto.

A prototipagem é, portanto, o processo de aproximação do produto com o propósito primordial de investigar fenômenos sujeitos a riscos e incertezas. $\mathrm{O}$ foco de investigação pode ser, por exemplo, o atendimento das expectativas de clientes em relação a um determinado produto. Beynon-Davies, Tudhope e Mackay (1999) destacam que uma importante característica da atividade de prototipagem é sua natureza experimental, envolvendo um ciclo repetitivo de tentativas que incluem produção do protótipo, avaliação e correção até que as expectativas do cliente sejam satisfeitas.

Ulrich e Eppinger (2011) classificam os protótipos em físicos e analíticos. Os primeiros constituem-se elementos tangíveis criados para aproximação do produto, enquanto que os analíticos caracterizam-se por representações intangíveis, normalmente construídas a partir de modelos matemáticos. Exemplos de modelos analíticos são simulações a partir de programas computacionais e modelos assistidos por softwares da área de projeto. Ainda, segundo os mesmos autores, o modelo analítico de um produto completo é denominado protótipo virtual, protótipo digital ou ainda mock up digital.

Uma segunda dimensão adotada por Ulrich e Eppinger (2011) para classificação dos protótipos diz respeito ao grau de abrangência dos atributos do produto contemplados no protótipo, e está associado à finalidade da investigação. Os protótipos são ditos completos quando incluem grande parte dos atributos do produto, ou mesmo todos eles, apresentando-se como uma versão operacional deste. Os protótipos classificados como focados abrangem um ou poucos atributos do produto e têm como finalidade investigar detalhadamente os aspectos contemplados. Uma vez que um protótipo consome recursos financeiros e tempo da etapa de desenvolvimento do produto (GRIMM, 2004), é natural que se questione o porquê de seu uso, que tipo de protótipo adotar (analítico ou físico) e se os mesmos devem ser completos ou focados. A seguir, esses aspectos são discutidos no contexto da construção civil.

\section{O EMPREgo DA PROTOTIPAGEM NA PRODUÇÃO DO AMBIENTE CONSTRUÍDO}

Existe uma natureza essencialmente dinâmica e iterativa no desenvolvimento de um projeto de edifício, sendo que o conceito do produto e o processo de validação das soluções propostas para continuidade de seu desenvolvimento ocorrem em loops investigativos (FAITHFULL; BALL; JONES, 2001). Smith e Reinertsen (1997) e Ulrich e Eppinger (2011) acrescentam que as mudanças são intensas e corriqueiras nas fases iniciais do projeto, o que justifica a utilização de protótipos analíticos, pois custam menos e oferecem tempo de resposta mais curto (Figura 1).

No entanto, a maior sofisticação do produto imobiliário tem levado ao aumento da complexidade no PDP, o que tem demandado a validação das informações de projeto a partir da confecção de protótipos físicos. Estes, por outro lado, dependem da consistência nas definições levantadas na concepção do projeto, que podem ser previamente validadas por protótipos analíticos, diminuindo as incompatibilidades e incertezas que impactam a produção.

O desenvolvimento de protótipos analíticos deve elucidar pontos obscuros relativos às soluções de projeto, permitindo que o enfoque no desenvolvimento do protótipo físico recaia sobre a redução do risco associado, principalmente ao processo de produção ou problemas atípicos 
Figura 1. Custos no processo de desenvolvimento do projeto e o emprego de protótipos. Baseada em Smith e Reinertsen (1997) de projeto. Embora o desenho 2D seja largamente utilizado na concepção e compatibilização de soluções de projeto, uma de suas principais características encontra-se no emprego de apenas duas dimensões para compreender espacialmente o ambiente projetado, acarretando limitações para representar graficamente e analisar as interfaces de partes do produto (FERREIRA, 2007). Nesse sentido, esse tipo de protótipo exige maior capacidade de abstração para ser analisado quando comparado a um protótipo analítico 3D, pois necessita de uma linguagem técnica para ser compreendido e reconstruído no imaginário de quem o lê (BONSIEPE, 2000).

Também é preciso esclarecer que a prototipagem analítica pode oferecer mais benefícios da visualização tridimensional realística do produto, hoje usual no mercado da arquitetura e engenharia (KALAY, 2006). A partir de aplicativos computacionais dinâmicos (CFD - Computational Fluid Dynamics) e da modelagem da informação de edifícios (BIM - Building Information Modeling), não apenas a representação geométrica de objetos físicos é comunicada, mas, também, todo um conjunto de dados abstratos pode ser associado a esse modelo (BOUCHLAGHEM, SHANG, et al., 2005; TSE, WONG; WONG, 2005; SUCCAR, 2009). Esse maior conjunto de atributos permite a simulação e a avaliação de diferentes aspectos relacionados ao produto e ao processo produtivo que auxiliam a tomada de decisão e a gestão na busca pelo desempenho esperado da edificação (ARAYICI et al., 2011).

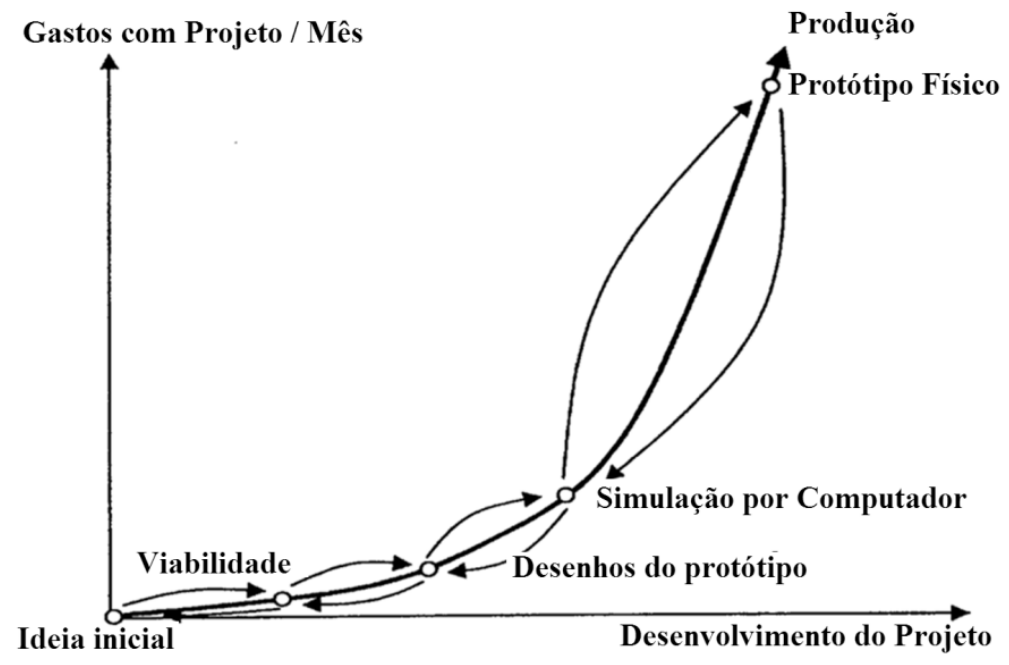

\section{MÉTODO DA PESQUISA}

\section{Contexto e delineamento metodológico}

O estudo exploratório que serviu de base para este artigo foi desenvolvido em parceria com uma empresa construtora e incorporadora que mantém como prática rotineira a construção de um protótipo físico da unidade habitacional como mecanismo de análise da construtibilidade e da integração entre os diferentes sistemas que a compõem. $O$ interesse da empresa e a oportunidade de acompanhamento, em tempo real, da execução de um dos protótipos motivou o desenvolvimento do estudo relatado neste artigo. Tratava-se de um edifício residencial composto por quatro torres com 19 pavimentos, resultando em 304 unidades habitacionais de médio padrão. A Figura 2 ilustra a planta simplificada da unidade habitacional (apartamento-tipo). 


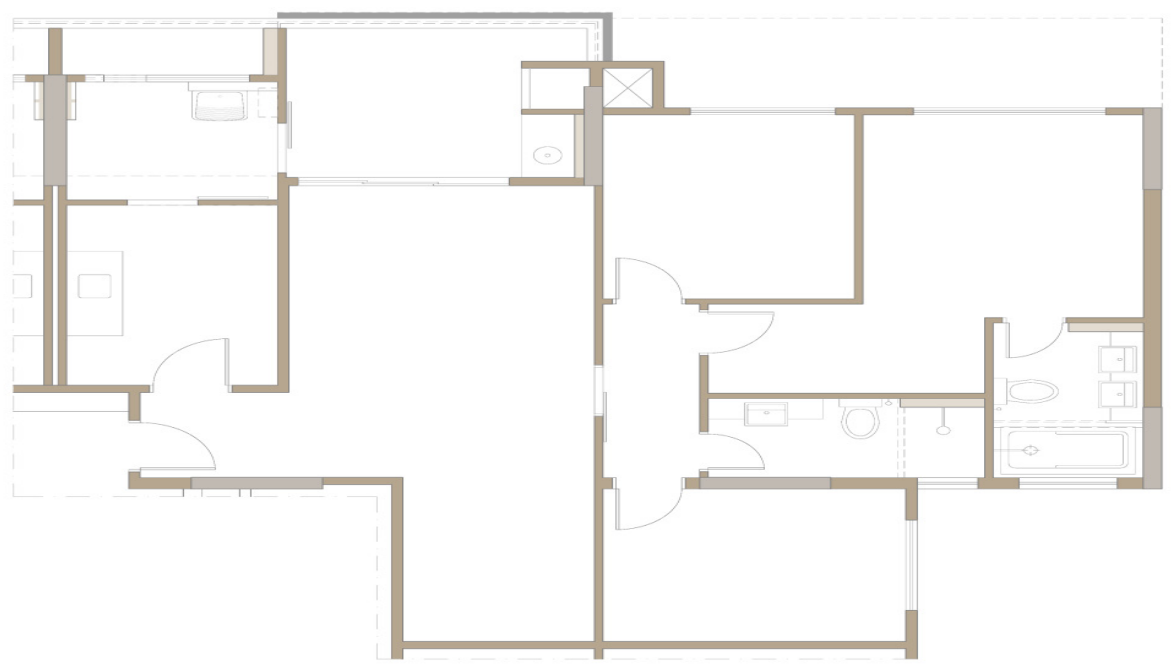

Sendo assim, para possibilitar a análise comparativa das prototipagens física, analítica 2D e 3D, foram constituídas três equipes incumbidas do desenvolvimento e da coleta de dados de cada modalidade de protótipo do apartamento-tipo. Conforme ilustra a Figura 3, os três protótipos foram realizados a partir de uma mesma base de dados composta por documentos fornecidos pela empresa, com objetivo de identificar inconsistências remanescentes no projeto.

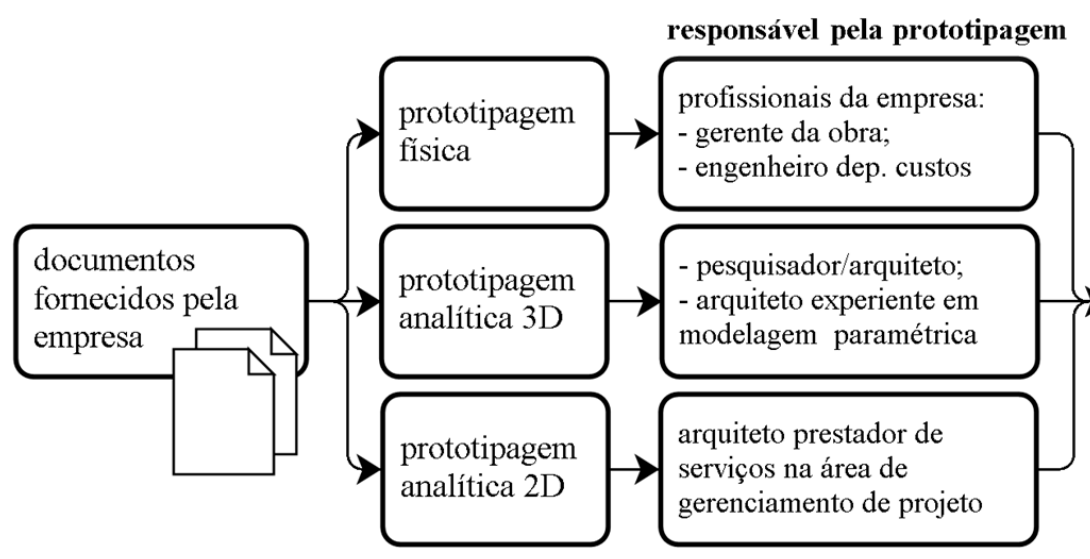

Figura 2. Planta simplificada do apartamento tipo. Adaptado do projeto arquiteônico original.

objetivo da prototipagem

identificar

inconsistências nos

projetos liberados para obra

Figura 3. Delineamento do processo de pesquisa.

No projeto executivo de arquitetura, foram analisadas 18 pranchas, entre as plantas e detalhamento de piso, esquadrias, áreas molhadas, varanda e áreas técnicas. No projeto de estrutura, foram analisadas 11 pranchas, contendo os arquivos de plantas de formas e detalhes, e plantas de perfurações na estrutura. No projeto de instalações elétricas, as plantas de automação, sistema de proteção de descargas atmosféricas, iluminação e tomadas, telefone e TV a cabo foram compatibilizadas. No projeto de instalações hidrossanitárias e gás, foram verificadas 8 pranchas, contendo as plantas de esgoto, águas pluviais, água fria, água quente, detalhes de esgoto e de água fria, esquemas de prumadas e esquemas isométricos de gás. Além disso, foi analisada 1 prancha contendo planta e detalhes de arcondicionado.

É importante salientar que essas pranchas foram compatibilizadas e liberadas para obra tanto pela empresa contratada para o desenvolvimento do projeto arquitetônico como pelo departamento de projetos da 
incorporadora-construtora responsável pelo empreendimento. Ou seja, os documentos disponibilizados eram resultado de uma análise prévia de inconsistências e foram considerados suficientes para orientar a execução.

A coleta de dados durante o desenvolvimento dos três protótipos foi guiada pelo protocolo apresentado no Quadro 1 e os dados resultantes foram registrados em planilhas. A seguir, será apresentado, de forma detalhada, o método de pesquisa adotado no desenvolvimento de cada um dos protótipos.

Quadro 1. Protocolo para coleta de dados

\begin{tabular}{|c|c|c|}
\hline & Objetivo da prototipagem & $\begin{array}{l}\text { Identificar inconsistências no projeto: problemas de interferência entre } \\
\text { subsistemas envolvidos }\end{array}$ \\
\hline 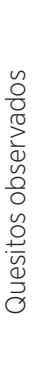 & $\begin{array}{l}\text { Interferência de detalhes de } \\
\text { acabamento }\end{array}$ & $\begin{array}{l}\text { Sistema estrutural x arquitetônico } \\
\text { Sistema estrutural x arquitetônico x hidráulico } \\
\text { Sistema estrutural x arquitetônico x elétrico } \\
\text { Sistema hidráulico x elétrico x ar-condicionado } \\
\text { Sobressalto no reboco devido à estrutura } \\
\text { Ponto de partida e paginação de revestimentos } \\
\text { Níveis e acabamentos de gesso } \\
\text { Interferência entre gesso e tubulações, interferência entre as tubulações. } \\
\text { Acabamento de churrasqueira e varanda } \\
\text { Interferência da varanda com a fachada }\end{array}$ \\
\hline
\end{tabular}

\section{Prototipagem física}

A execução do protótipo físico de uma unidade habitacional foi acompanhada por dois engenheiros civis, funcionários da empresa construtora. Um deles é engenheiro pleno responsável pela obra (com cerca de 6 anos de experiência profissional) e o outro, também engenheiro pleno, atua no departamento de orçamentação da empresa (com cerca de 10 anos de experiência profissional). Esses profissionais possuíam as mesmas pranchas de projeto disponibilizadas para as equipes responsáveis pelos protótipos analíticos 2D e 3D e também seguiram o mesmo protocolo de coleta de dados apresentado no Quadro 1.

Como exemplifica a Figura 4, o foco dessa prototipagem era identificar antecipadamente problemas de interferências dos diferentes sistemas embutidos ou com interfaces com a alvenaria, de forma a facilitar o processo de produção. Nele, foi executada toda a vedação de um apartamento-tipo, suas instalações elétricas e hidráulicas, esquadrias e revestimentos internos. O acompanhamento e coleta de dados foram feitos por um período de três meses, o que correspondeu ao tempo de execução do protótipo.

Figura 4. Prototipagem física para antecipar problemas de interferencias entre subsistemas.

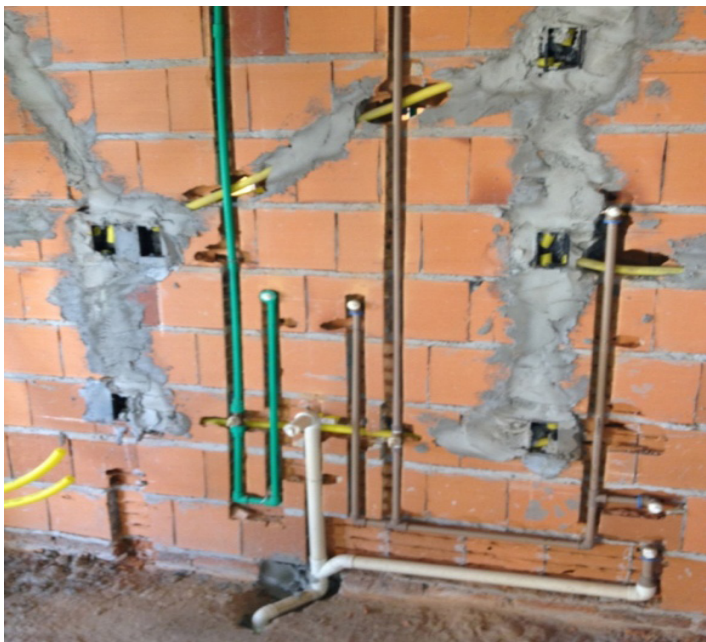




\section{Prototipagem Analítica 2D}

Para a análise das contribuições da prototipagem analítica 2D, considerou-se o conjunto de projetos em formato DWG, como o próprio protótipo (ULRICH; EPPINGER, 2011) e foi designado um arquiteto com experiência em coordenação de projetos e orçamentação, com escritório próprio consolidado no mercado e que presta serviços a grandes construtoras e incorporadoras de São Paulo e do Paraná. Nessa análise, foram utilizados os arquivos dos projetos executivos liberados para a obra, sem as correções oriundas do protótipo físico focado.

Prototipagem Analítica 3D

Dois outros arquitetos envolveram-se com a prototipagem analítica 3D. Um deles é projetista junior, com experiência na modelagem paramétrica, inclusive desenvolvendo treinamentos para uso do software Revit Suite. O outro arquiteto é, também, o pesquisador responsável pelo estudo, possui experiência profissional como projetista e coordenador de projetos, porém, possui pouca experiência no uso de software de modelagem.

Nessa atividade, foram utilizados os mesmos arquivos dos projetos executivos liberados para a obra sem as correções oriundas do protótipo físico focado. Projeto arquitetônico, estrutural e demais subsistemas foram modelados seguindo as informações prescritas nas pranchas do executivo, resultando em um modelo ilustrado pela Figura 5. As inconsistências foram identificadas durante a modelagem e a partir do recurso clash detection disponível no software.

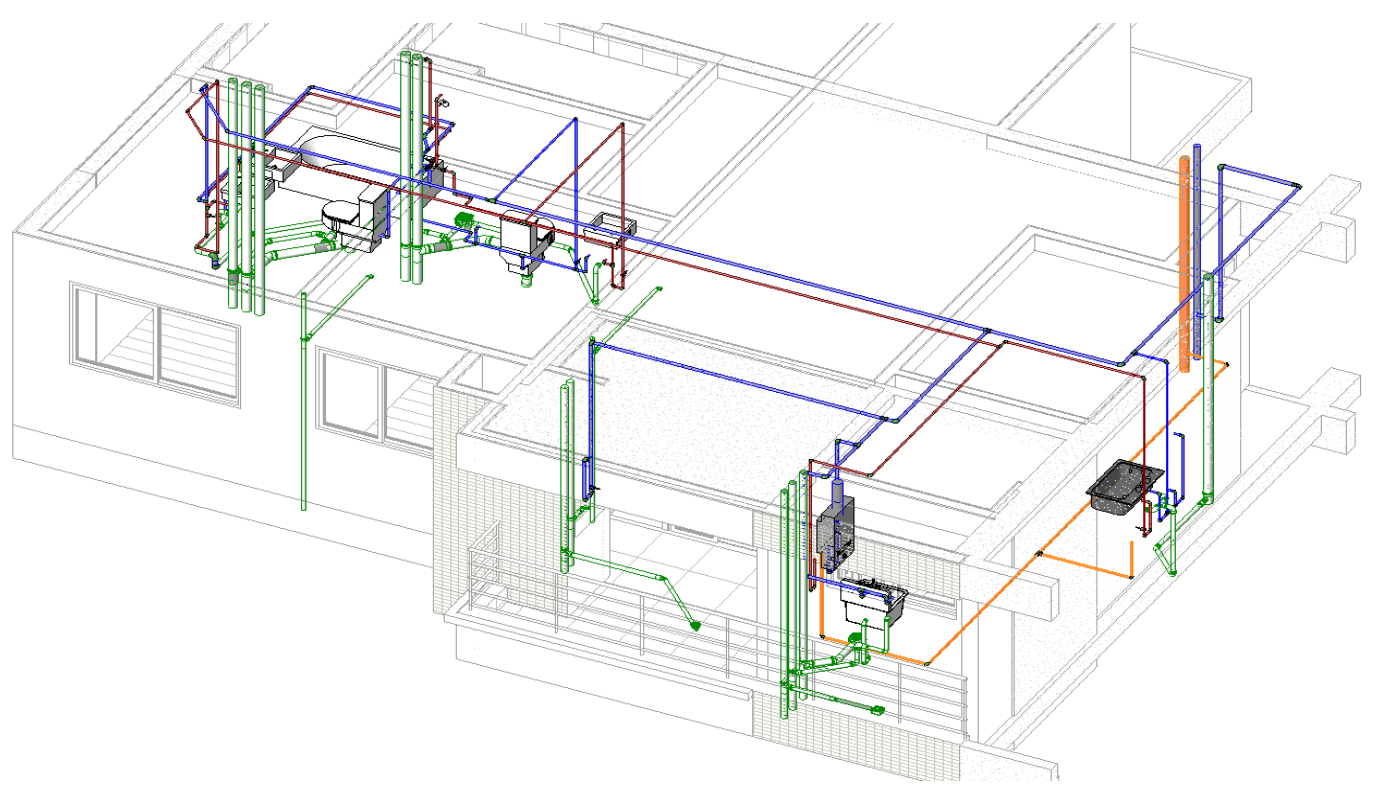

\section{Procedimentos adotados para análise dos dados}

Primeiramente, os dados coletados na prototipagem física foram tabelados e as relações de ganhos, ou não prejuízos, decorrentes de possíveis retrabalhos, foram computadas. Nas prototipagens analíticas, os profissionais responsáveis elencaram os problemas de inconsistências. Além disso, no exercício de análise das inconsistências do protótipo analítico 2D, foi registrado também um conjunto de inconsistências de desenhos de projetos. As inconsistências de cada tipo de protótipo foram classificadas conforme critério apresentado no Quadro 2.
Figura 5. Modelagem parametrica da arquitetura, estruturas e subsistemas hidrosanitários. 
Quadro 2. Descrição da classificação adotada para as inconsistências de projeto.

\begin{tabular}{|l|l|}
\hline Tipo I & $\begin{array}{l}\text { Inconsistência de pouca gravidade, com baixo ou nenhum grau de interferência com outras disciplinas e nenhum } \\
\text { impacto significativo sobre a obra. }\end{array}$ \\
\hline Tipo II & $\begin{array}{l}\text { Inconsistência de média gravidade, com baixo ou médio grau de interferência com outras disciplinas e médio } \\
\text { impacto no custo da obra (até } \mathrm{R} \$ 5.000,00) .\end{array}$ \\
\hline Tipo III & $\begin{array}{l}\text { Inconsistências de alta gravidade, com alto grau de inteferência com outras disciplinas e impacto grave no custo } \\
\text { da obra (acima de } \mathrm{R} \$ 5.000,00) .\end{array}$ \\
\hline
\end{tabular}

Os valores apontados no Quadro 2 fazem referência aos custos decorrentes da não detecção das inconsistências observadas. Eles foram mensurados pelo setor de orçamentação da empresa colaboradora, adotando bases reais de cálculo empregadas para dimensionar os prejuízos decorrentes de retrabalho. Devido às limitações contextuais do trabalho, esses custos compreendem apenas as perdas diretas, associadas ao material e ao retrabalho realizado. Não são considerados, portanto, os prejuízos indiretos, decorrentes de atrasos no cronograma ou eventuais impactos na qualidade final do produto.

Como o objetivo do artigo é estabelecer um paralelo entre protótipos físico e analítico, confrontando o desempenho de cada modalidade na detecção de inconsistências de projeto de modo a apresentar uma relação de eficiência e economia entre elas, foi preciso diferenciar falhas que diziam respeito apenas às particularidades do desenho no CAD daquelas inconsistências que realmente impactariam em custos adicionais e retrabalho caso não fossem detectadas antecipadamente. Essa correção é importante para eliminar distorções nos resultados que implicariam em uma leitura equivocada. Assim, foram propostos dois filtros para as inconsistências detectadas no estudo.

No primeiro filtro, foram ignoradas as inconsistências detectadas nas prototipagens analíticas que não foram detectadas na prototipagem física, aceitando apenas aquelas que se relacionavam às inconsistências detectadas e mensuradas pela empresa construtora. Dessa forma, foi possível mensurar financeiramente junto à construtora a totalidade das despesas diretas economizadas e, assim, identificar o potencial de economia que os tipos de prototipagem analítica alcançaram.

No segundo filtro, foram descontadas das inconsistências detectadas na prototipagem física e prototipagem analítica 3D paramétrica todas as inconsistências que foram detectadas na compatibilização 2D. Assim, projetou-se uma situação ideal, em que todas as inconsistências detectadas da maneira tradicional seriam detectadas e resolvidas ainda na etapa de projeto. Dessa forma, as inconsistências restantes detectadas no protótipo analítico 3D e no protótipo físico compreendem apenas as inconsistências que dificilmente seriam detectadas pelo protótipo analítico 2D.

Resultados e discussões

Os dados coletados e compilados de acordo com o Quadro 2 permitiram obter a quantidade de inconsistências para os três tipos de protótipos. Esses resultados são apresentados no Quadro 3. O maior volume de observações apontadas na análise do protótipo analítico 2D está vinculado a uma distorção no entendimento entre inconsistências nas informações de projeto e problemas encontrados nos desenhos CAD, que não prejudicavam o entendimento do projeto. Esse último tipo de problema não foi sequer considerado pelas equipes responsáveis pelo protótipo físico e analítico $3 \mathrm{D}$, pois se relaciona às dificuldades particulares da representação 2D, não impactando na interpretação equivocada do projeto que pudesse levar a uma falha na execução. Foram considerados, porém, erros de desenho que impactam na interpretação do projeto durante a etapa de execução.

Quadro 3. Quantidade de inconsistências identificadas.

\begin{tabular}{c|c|c|c|}
\hline Tipo de análise & Protótipo físico & Protótipo analítico 3D & Protótipo analítico 2D \\
\hline № inconsistências & 15 & 33 & 51 \\
\hline
\end{tabular}

Como em uma prancheta de desenho, plantas, cortes, elevações, detalhes ou quaisquer outras peças gráficas são desenvolvidas separadamente e, conforme as soluções evoluem, ocorrem eventuais modificações em um desses desenhos, exigindo um esforço adicional e permanente de compatibilização entre áreas de conhecimento envolvidas. A fragmentação das informações de projeto decorrentes da não compatibilização ou uma compatibilização insuficiente se tornam mais comuns quando realizados com desenhos 2D (FERREIRA, 2007), dificultando análises e correlações entre as informações desenvolvidas por cada disciplina e disponibilizadas para a execução. Como as equipes responsáveis pela concepção do projeto e pela execução, normalmente, são diferentes e há dificuldade em retificar rapidamente as inconsistências, são adotadas soluções baseadas na experiência dos profissionais de canteiro sem que a inconsistência seja registrada.

Assim, problemas como "posição do vaso sanitário está deslocada $8 \mathrm{~cm}$ ”, apresentada como uma incompatibilidade do protótipo analítico 2D, apenas ocorrem quando projetistas trabalharam com bases 
diferentes. Esse tipo de problema de desenho foi detectado diversas vezes na análise do protótipo analítico 2D a partir da sobreposição das pranchas arquitetônicas e hidráulicas, por exemplo. Divergências desse gênero não foram relatadas pelos responsáveis pela construção do protótipo físico, pois estes não consideram que inconsistências desse gênero prejudiquem a construção. Seguindo o mesmo exemplo entre inconsistências de desenho das pranchas arquitetônicas e hidráulicas, o projeto hidráulico, normalmente, não apresenta cotas para posicionamento desses equipamentos e, por isso, a equipe de execução buscou soluções no projeto arquitetônico, no qual havia informações textuais e medidas cotadas.

No entanto, para o coordenador de projetos técnicos que está preocupado com a qualidade do conteúdo e a assertividade da documentação liberada para obra, essa constatação é corretamente entendida como preocupante. Fato é que quando realizada a confrontação das pranchas 2D a partir da sobreposição, os erros se tornaram redundantes, sendo repetidos conforme as plantas e cortes se multiplicavam nos desenhos técnicos dos diversos subsistemas.

Não apenas a redundância dos erros, mas a fragmentação das informações, registradas cada uma segundo um padrão individual das empresas terceirizadas de projeto, contribuem para a dificuldade de leitura dos projetos técnicos e, em decorrência disso, para a dificuldade de compatibilização e diminuição da confiabilidade de seus desenhos técnicos. Como pode ser visto no Quadro 4, cada especialidade compõe seu próprio conjunto de layers, que melhor se adequa às informações tratadas. Essa prática dificulta a integração dos projetos do produto, pois ocasiona duplicidade e ambiguidade de informações.

Quadro 4. Quantidade de layers do projeto.

\begin{tabular}{lcc}
\hline & Quantidade de Layers \\
\hline Arquitetônico & 42 \\
Ar-condicionado & 37 \\
Esgoto/água pluvial & 92 \\
Água fria/água quente & 97 \\
Automação & 152 \\
SPDA & 144 \\
Elétrico & 152 \\
Estrutural & 83 \\
Furação & 108 \\
Telemática & 151 \\
Soma de Layers dos 10 arquivos & 1.058 \\
Layers efetivamente utilizados & 206 \\
\hline
\end{tabular}

Para diminuir esses problemas, a coordenação dos projetos técnicos pode promover a adoção de padrões compatíveis de layers. Porém, essa medida desafia barreiras relacionadas à cultura organizacional das empresas terceirizadas, exige treinamento e diminui, inicialmente, a produtividade em um tipo de contrato que, normalmente, ocorre exclusivamente para um ou alguns projetos.

Essas e outras ocorrências demonstram a fragilidade do processo atual de validação das informações de projeto para liberação para obra, pois dependem diretamente da competência individual de análise de profissionais especializados em compatibilização. Além de seu caráter não produtivo, essas análises estão sempre sujeitas a falhas de atenção ou competência, resultando na não detecção de erros decorrentes de inconsistência entre as informações dos projetos.

Observou-se que esse tipo de problema, como a multiplicidade de layer, está ligado às particularidades do desenvolvimento do projeto com base em ferramentas CAD 2D. Em decorrencia disso, não foi relacionado entre as 
inconsistências do protótipo físico nem foi computado nos custos relatados. A detecção dessas inconformidades de desenho significa, porém, um tipo de inconsistência que aumenta as incertezas que impactam sobre o PDP, evidenciando a necessidade de empregar ferramentas mais eficazes para 0 desenvolvimento do projeto.

Com relação à discussão apresentada neste tópico relacionada aos projetos desenvolvidos e documentados com ferramentas CAD - e que este trabalho enquadra como um protótipo analítico 2D - são apontadas algumas conclusões preliminares: (01) é importante realizar uma análise aprofundada e detalhada sobre a documentação entregue para produção, muitas vezes negligenciada; (02) há uma crescente dificuldade em promover a integração de projetos por intermédio da coordenação baseada em compatibilização - na qual os conflitos são detectados e resolvidos por meio da sobreposição de pranchas e revisão de versões finalizadas; e (03) o processo de desenvolvimento de projetos a partir de desenhos bidimensionais em ferramentas CAD é deficiente, uma vez que desloca a atenção dos projetistas e coordenadores para problemas de representação do projeto que não agregam valor ao produto e negligencia a interface de comunicação entre os agentes envolvidos no PDP.

\section{Depurando os dados levantados}

A análise da prototipagem analítica virtual 2D permitiu corrigir distorções relacionadas a eventuais deficiências na coordenação e na compatibilização dos projetos técnicos utilizados como base de informação para desenvolver os protótipos físico e analítico 3D.

Essas eventuais deficiências no processo de coordenação são, em parte, provenientes e justificadas pela relação cooperativa existente entre escritórios de projeto e construtoras envolvidos no empreendimento que serviu de base para o estudo. Essa prática facilita a comunicação e aumenta o comprometimento entre os intervenientes envolvidos, porém, para o fim da pesquisa, foi considerada como uma variável a ser corrigida para validade do estudo de comparação entre os tipos de prototipagem observados.

Nesse sentido, a análise da prototipagem analítica virtual 2D realizada para o estudo caracteriza-se como uma nova compatibilização dos projetos técnicos, realizada posteriormente ao encerramento da etapa de projeto, apontando, assim, quais são os reais limites onde a coordenação baseada em compatibilização pode chegar na prática, sem auxílio da modelagem paramétrica ou da prototipagem física.

Por outro lado, como foi visto na seção anterior, muitas das inconsistências de projeto detectadas nessa compatibilização posterior se confundem com inconformidades de projeto que não impactam na qualidade da produção, quando muito, na confiabilidade das informações. Da mesma forma, algumas inconsistências observadas pela prototipagem analítica virtual paramétrica se relacionavam a essas inconformidades de projeto, pois utilizou como base os arquivos digitais das pranchas de projeto.

O Quadro 5 apresenta, na segunda coluna, o resultado observado com a construção do protótipo físico na própria edificação. Essa prototipagem antecipou quinze inconsistências que foram resolvidas antes do início da produção dos pavimentos-tipos (quatro apartamentos por andar, quinze pavimentos por torre, quatro torres), evitando custos adicionais estimados em $\mathrm{R} \$ 70.814,00$ por torre. Como o empreendimento era composto por quatro torres, a prototipagem física resultou em um total de $\mathrm{R} \$ 283.256,00$ de economia ao empreendimento. 
Quadro 5. Relação da quantidade e de custos estimados das inconsistências identificadas no protótipo físico também identificadas no protótipo analítico virtual.

\begin{tabular}{lccc|}
\cline { 2 - 4 } \multicolumn{1}{c}{} & \multicolumn{2}{c|}{ Inconsistências também indentificadas no Protótipo Físico } \\
\hline \multicolumn{1}{c}{ Tipo de análise } & Protótipo físico & Protótipo analítico 3D & Protótipo analítico 2D \\
\hline № inconsistências & 15 & 13 & 6 \\
Tipo I & 6 & 5 & 1 \\
Tipo II & 3 & 3 & 2 \\
Tipo III & 6 & 5 & 3 \\
& $100 \%$ & $86,67 \%$ & $40 \%$ \\
Custo evitado $(\mathrm{R} \$)$ & $70.814,00$ & $63.276,00$ & $27.736,00$ \\
\hline
\end{tabular}

O mesmo quadro apresenta, na terceira coluna, um total de 13 inconsistências que também foram detectadas pelo protótipo analítico 3D, representando $86,67 \%$ das inconsistências apontadas pelo protótipo físico. Tratam-se das mesmas inconformidades encontradas no protótipo físico desenvolvidos pela construtora, o que representa a economia estimada de $\mathrm{R} \$ 63.276,00$ em uma torre e $\mathrm{R} \$ 253.104,00$ em todo o empreendimento. Esse custo foi calculado a partir do custo de cada uma das 13 inconsistências detectadas e representa $89,35 \%$ do custo total estimado detectado pelo protótipo físico.

Por sua vez, na quarta coluna, a análise de compatibilização de projetos conseguiu apontar 6 das 15 inconsistências que foram observadas no protótipo físico, ou seja, identificou $40 \%$ dos itens detectados pelo protótipo físico. Essa performace implica uma economia de $\mathrm{R} \$ 27.736,00$ de custos estimados, decorrente de recursos não desperdiçados na execução de uma torre e R $\$ 110.944,00$ na execução das quatro torres. O custo economizado detectado pela compatibilização de projetos corresponde a $39,17 \%$ do valor antecipado pelo protótipo físico. Uma vez que os valores relacionados na quarta coluna se baseiam no mesmo método de compatibilização empregado na fase de projeto, os mesmos (seis itens) foram desconsiderados como fatores de correção para a comparação entre protótipos fisico e analítico 3D, apresentado no Quadro 6.

Quadro 6. Relação da quantidade e de custos estimados das inconformidades identificadas no protótipo físico também identificadas no protótipo analítico virtual.

\begin{tabular}{|lccc|}
\cline { 2 - 4 } \multicolumn{1}{c|}{} & \multicolumn{3}{c|}{ Total descontando o protótipo representativo } \\
\hline \multicolumn{1}{c}{ Tipo de análise } & Protótipo físico & Protótipo analítico 3D & $\% 1$ \\
\hline № não conformidades & 9 & 8 & $88,88 \%$ \\
Tipo I & 5 & 4 & $80,00 \%$ \\
Tipo II & 1 & 1 & $100,00 \%$ \\
Tipo III & 3 & 3 & $100,00 \%$ \\
Custo evitado (R $\$)$ & $43.078,00$ & $43.078,00$ & \\
\hline
\end{tabular}

* Percentual resultante da proporção dos resultados do protótipo virtual em relação ao protótipo físico.

Dessa forma, restaram nove inconsistências encontradas no protótipo físico e oito encontradas no protótipo analítico 3D, o que significa uma proporção de $88,88 \%$ do segundo em relação ao primeiro. Porém, os custos evitados por ambas as modalidades correspondem ao valor total de $\mathrm{R} \$ 43.078,00$ para cada torre. Essa coincidência ocorreu porque o item identificado apenas no protótipo físico corresponde ao tipo I, que representa um custo nulo ou insignificante.

No caso estudado, o protótipo físico anteviu mais itens que o protótipo virtual, significando, contudo, a mesma economia em recursos financeiros. Por outro lado, destaca-se que a construção do protótipo físico da forma como foi realizada, isto é, dentro da própria estrutura da edificação, posterga demasiadamente as constatações, ao passo que o protótipo analítico 3D pode levantá-las previamente. A atividade de prototipagem analítica 3D pode ser realizada ainda na fase de projeto executivo, antes de sua validação final para liberação da obra. 
Além disso, existe uma limitação do protótipo físico, possível apenas nas partes da construção passíveis de reprodução. Para aumentar a confiabilidade do projeto e do processo de construção em todo o edifício, o desenvolvimento do protótipo analítico ou a elaboaração de maquetes se revelam as únicas alternativas viáveis. Embora os dados detalhados que compõem os custos indiretos do protótipo físico não tenham sido disponibilizados pela construtora, é possivel calcular os custos resultantes do trabalho realizado pela equipe de pesquisa na modelagem como um dado referencial para compreender os custos que essa atividade respresenta para o empreendimento frente à economia já demonstrada. Foi contabilizado o tempo despendido para realizar o protótipo analítico virtual, totalizando 32 horas de trabalho entre organização dos arquivos, desenvolvimento dos protótipos tridimensionais, análise das não compatibilidades, e confecção de relatórios.

Com o intuito de calcular o valor do serviço de compatibilização de projetos, considerando-se a terceirização desse serviço para uma empresa formal de arquitetura com arquitetos registrados conforme legislação vigente, foi adotado o valor do piso salarial da categoria (9 Salários Mínimos para jornada diária de oito horas de trabalho), cujo valor na época deste estudo era de $\mathrm{R} \$ 678,00$ por mês (maio de 2013), totalizando $\mathrm{R} \$$ $6.102,00$. O custo desse funcionário para a empresa, registrado conforme a CLT (Consolidação das Leis Trabalhistas), segundo o TCPO - Tabelas de Composições de Preços para Orçamentos, da Editora Pini, em sua $13^{\mathrm{a}}$ edição, considerando-se os encargos básicos e obrigatórios, incidentes e reincidentes, e complementares, é de aproximadamente $132,91 \%$ do valor de registro do salário, ou seja, $\mathrm{R} \$ 8.110,17$, o que totaliza $\mathrm{R} \$ 14.212,17$. Considerando-se o mês com vinte dias úteis e jornada de trabalho de oito horas diárias, temse o total mensal de cento e sessenta horas úteis de trabalho. Dessa forma, obtém-se, como custo de produção, o valor de $\mathrm{R} \$ 88,83$ por hora de trabalho.

Considerando como média dos custos (fixos e variáveis) do escritório de arquitetura a proporção de $30 \%$ do preço de venda do serviço, conforme recomendações de profissionais do mercado, como da Incubadora de Empresas da Universidade Estadual do Ceará (2015) e como margem de lucro o valor de $32 \%$, conforme alíquota adotada como padrão de lucro para Pequenas e Médias Empresas - PME (2015) sobre o qual incide o Imposto de Renda, tem-se as proporções médias que ajudarão a calcular o mark-up.

O mark-up é um valor que auxilia na composição do preço de venda do produto ou serviço, que multiplica o valor do custo, nesse caso, o custo da contratação de um profissional para a execução do serviço, para se chegar ao preço de venda final. Leva em consideração os custos fixos, como aluguel, telefone, salários dos funcionários administrativos, etc. e custos variáveis, como impostos incidentes e, também, a margem de lucro desejada. O valor do mark-up (MU) é calculado conforme a seguinte fórmula:

$\mathrm{MU}=100 \% /(100 \%-\mathrm{C}-\mathrm{ML})$

Onde $\mathrm{C}=$ Custos fixos e variáveis* e $\mathrm{ML}=$ Margem de Lucro (em percentual).

No caso apresentado, o mark-up (MU) calculado é de 2,63, fator a ser aplicado ao custo de produção do serviço prestado, nesse caso o valor de $\mathrm{R} \$ 88,83 / \mathrm{h}$, o que resulta no valor por hora a ser cobrado do serviço de $\mathrm{R} \$$ $233,63 / \mathrm{h}$.

Foram registradas trinta e duas horas para a execução do serviço de compatibilização de projetos, o que totaliza o valor de $\mathrm{R} \$ 7.475,84$ para a prototipagem analítica virtual (Quadro 7).

Esse valor corresponde a 4,34\% do custo total (R $\$ 172.312,00)$ de inconformidades evitadas pela prototipagem física na execução da torre. Porém, os ganhos possíveis com a modelagem não se restringem à economia aqui apresentada. Ao se antecipar os problemas antes do início da execução da obra, é possível corrigir os projetos antes de sua liberação final, evitando também mudanças no planejamento - cronograma de obra e orçamento. 
QUADRO 7. Cálculo de honorários de Compatibilização de Projetos.

\begin{tabular}{lc}
\hline Salário mínimo & $\mathrm{R} \$ 678,00$ \\
9 Salários mínimos (piso salarial Arquiteto para 8 h de trabalho semanal) & $\mathrm{R} \$ 6.102,00$ \\
Encargos sociais (segundo TCPO) - 132,91\% & $\mathrm{R} \$ 8.110,17$ \\
Total (Custo do serviço) (01 Arquiteto x 1 mês) & $\mathrm{R} \$ 14.212,17$ \\
& $160 \mathrm{~h}$ \\
Total de horas de trabalho por mês (8 h x 20 dias) & $\mathrm{R} \$ 88,83$ \\
Custo do serviço (01 arquiteto) por hora & $30 \%$ \\
$\mathrm{C}=$ Custos (Fixos + Variáveis) & $32 \%$ \\
ML = Margem de Lucro (PME) & 2,63 \\
Mark-up [MU = 100\%/(100\%-C-ML) & $\mathrm{R} \$ 233,63$ \\
Preço de venda do serviço (01 arquiteto) por hora = R $\$ 88,83 \times 2,64$ & $\mathrm{R} \$ 7.475,84$ \\
Preço total do serviço = 32 h $\times \mathrm{R} \$ 233,62$ & \\
\hline
\end{tabular}

\section{Detalhamento das inconsistências observadas}

Após apresentar o desempenho econômico verificado em cada modalidade de prototipagem, cuja análise apresentou observações globais sobre o problema relacionado às inconsistências observadas, cabe ainda destacar alguns exemplos significativos que melhor caracterizem as análises que se seguirão. O Quadro 8 apresenta a relação das inconsistências listadas por cada equipe envolvida no experimento. Nele estão discriminados e classificados os itens que se enquadraram no critério especificado no Quadro 2, que considera o impacto causado na obra. Dessa relação, alguns casos foram tomados como exemplo e analisados a seguir.

Quadro 8. Inconsistências identificadas pelo Protótipo Físico, classificadas segundo impacto em obra, e pelos protótipos analíticos correspondentes.

\begin{tabular}{|c|c|c|c|c|}
\hline $\mathrm{n}^{0}$ & Protótipo físico & Tipo & Protótipo analítico 3D & Protótipo analítico 3D \\
\hline 1 & $\begin{array}{l}\text { Elevação da alvenaria até o fundo da } \\
\text { laje para redução de ruídos e odores }\end{array}$ & I & $\begin{array}{l}\text { Falta definição da interface entre } \\
\text { paredes do banheiro e a laje. }\end{array}$ & $\begin{array}{l}\text { Parede alvenaria } 12 \mathrm{~cm} \text { entre } \\
\text { apartamentos, com laje nervurada: } \\
\text { confirmar isolamento acústico } \\
\text { (alvenaria entra nos vãos das } \\
\text { cubetas?). }\end{array}$ \\
\hline 2 & $\begin{array}{l}\text { Alteração no caminhamento do } \\
\text { esgoto do tanque permitiu retirar o } \\
\text { shaft de dentro da área de serviço, } \\
\text { aumentando o espaço interno. }\end{array}$ & $\|$ & $\begin{array}{l}\text { Locação do QLD e QC não } \\
\text { coincide, enchimento está locado } \\
\text { errado ou era destinada a outra } \\
\text { finalidade não expressa. }\end{array}$ & $\begin{array}{c}\text { Furo na laje de piso não aparece na } \\
\text { planta de EST atrás de QC e QDL }\end{array}$ \\
\hline 3 & $\begin{array}{l}\text { Eliminação de um shaft do Banheiro } \\
\text { da Suíte, aumentando o espaço } \\
\text { interno e melhorando o aspecto do } \\
\text { acabamento. }\end{array}$ & III & $\begin{array}{l}\text { Shafts do banheiro subutilizados, } \\
\text { as tubulações podem ser locadas } \\
\text { no banho } 1 \text { onde o shaft parece } \\
\text { interferir menos no espaço }\end{array}$ & - \\
\hline 4 & $\begin{array}{c}\text { No projeto de furação de vigas } \\
\text { faltaram } 5 \text { furos para a tubulação } \\
\text { de elétrica. Projeto estrutural previa } \\
\text { apenas } 6 \text { furos horizontais para } \\
\text { passagem de tubulação elétrica. Real } \\
\text { necessidade: } 3 \text { furos para automação, } \\
4 \text { furos para elétrica, } 4 \text { furos de } \\
\text { telefonia e TV. }\end{array}$ & III & $\begin{array}{c}\text { O projeto elétrico prevê } 6 \\
\text { furos, mas são insuficientes, } \\
\text { contabilizamos } 11 .\end{array}$ & $\begin{array}{c}\text { Previstos } 3 \text { furos na viga V514-3. } \\
\text { ELE confirmar: é possível juntar as } \\
\text { tubulações em um só furo maior? } \\
\text { Qual h? Qual dimensão? }\end{array}$ \\
\hline 5 & $\begin{array}{l}\text { Projeto estrutural não contemplava } \\
\text { furos para passagem de split e } \\
\text { eletrodutos no Dormitório } 2 .\end{array}$ & III & - & - \\
\hline 6 & $\begin{array}{c}\text { Projeto estrutural não contemplava } \\
\text { diâmetros necessários para passagem } \\
\text { de rede frigorígena }\end{array}$ & III & $\begin{array}{c}\text { A tubulação frigorifica entra } \\
\text { em conflito com a tubulação } \\
\text { de esgoto. As furações na viga } \\
\text { e pilar restringem os desvios } \\
\text { destas tubulações }\end{array}$ & $\begin{array}{l}\text { Posição da tubulação de AF e ES } \\
\text { estão representadas na mesma } \\
\text { localização, dentro do EH. }\end{array}$ \\
\hline
\end{tabular}


Quadro 8. Continuação...

\begin{tabular}{|c|c|c|c|c|}
\hline $\mathrm{n}^{\circ}$ & Protótipo físico & Tipo & Protótipo analítico 3D & Protótipo analítico 3D \\
\hline 7 & $\begin{array}{l}\text { Projeto estrutural não contemplava } \\
\text { furação dos drenos do split }\end{array}$ & 1 & $\begin{array}{l}\text { Furação para dreno não esta } \\
\text { prevista (Dormitório 2) }\end{array}$ & $\begin{array}{l}\text { Não há tubulação de dreno para } \\
\text { AC do ambiente }\end{array}$ \\
\hline 8 & $\begin{array}{c}\text { Projeto elétrico solicita instalações de } \\
\text { caixas } 4 \times 2 \text { ", onde não há espaço na } \\
\text { alvenaria }(9 \mathrm{~cm})\end{array}$ & 1 & - & - \\
\hline 9 & $\begin{array}{l}\text { Havia uma tomada na altura da } \\
\text { rodabanca da bancada da cozinha }\end{array}$ & III & $\begin{array}{l}\text { Interferência entre espelho de } \\
\text { granito e tomada na cozinha }\end{array}$ & - \\
\hline 10 & $\begin{array}{l}\text { Projeto de gás não especificou o local } \\
\text { da saída do duto do aquecedor }\end{array}$ & I & $\begin{array}{l}\text { Apesar da indicação no detalhe } \\
\text { genérico, não houve a previsão } \\
\text { de saída para a chaminé do } \\
\text { aquecedor instantâneo a gás. }\end{array}$ & - \\
\hline 11 & $\begin{array}{c}\text { Projeto de gás não levou em } \\
\text { consideração fixação do tanque e o } \\
\text { ralo da Área de Serviço. }\end{array}$ & $\|$ & $\begin{array}{l}\text { Tubulação de gás entra em } \\
\text { conflito com sistema de esgoto. } \\
\text { A representação do traçado do } \\
\text { gás está indicada na prancha } \\
\text { das águas quentes e frias, que } \\
\text { ignora o traçado do esgoto, não } \\
\text { acusando esse erro. }\end{array}$ & $\begin{array}{c}\text { Tubulação de Gás cruzando com } \\
\text { tubulação de Esgoto, Água fria, } \\
\text { Água quente e Elétrica sobre o } \\
\text { tanque. }\end{array}$ \\
\hline 12 & $\begin{array}{l}\text { O projeto hidráulico necessitava de } \\
\text { um shaft de } 30 \mathrm{~cm} \text { no TQ da Área } \\
\text { de Serviço. O projeto arquitetônico } \\
\text { reservou um espaço de } 15 \mathrm{~cm} \text {. }\end{array}$ & $\|$ & $\begin{array}{c}\text { O dimensionamento da } \\
\text { tubulação inviabiliza a instalação } \\
\text { como proposta. A prumada } \\
\text { horizontal que passa sobre os } \\
\text { pontos hidráulicos indicados } \\
\text { no arquitetônico extrapolam os } \\
\text { limites do enchimento hidráulico. }\end{array}$ & - \\
\hline 13 & $\begin{array}{l}\text { O projeto hidráulico especificou um } \\
\text { caimento no esgoto da cozinha que } \\
\text { ultrapassava o pé-direito especificado } \\
\text { no projeto arquitetônico. }\end{array}$ & 1 & $\begin{array}{c}\text { A tubulação de esgoto se } \\
\text { aproxima muito do nível de } \\
\text { gesso do pavimento inferior. } \\
\text { Para atender a especificação de } \\
\text { inclinação, o controle em obra } \\
\text { tem aqui um ponto critico na } \\
\text { execução. }\end{array}$ & - \\
\hline 14 & $\begin{array}{c}\text { Pilar e altura da viga restrigem } \\
\text { posicionamento do duto de fumaça } \\
\text { da churrasqueira. }\end{array}$ & । & $\begin{array}{l}\text { A churrasqueira não é detalhada, } \\
\text { no caso de modulo de } \\
\text { churrasqueira, o pilar e a viga } \\
\text { semidivertida podem interferir no } \\
\text { traçado e inclinação do duto de } \\
\text { exaustão. }\end{array}$ & - \\
\hline 15 & $\begin{array}{l}\text { Impossibilidade de sobreposição de } \\
\text { caixas de split, conforme especificado } \\
\text { em arquitetônico devido à espessura } \\
\text { das caixas ser bem maior que a } \\
\text { espessura da alvenaria. }\end{array}$ & III & $\begin{array}{c}\text { Possível incompatibilidade } \\
\text { tecnológica: Confirmar } \\
\text { viabilidade de instalação de Split } \\
\text { em parede de } 9 \mathrm{~cm}\end{array}$ & - \\
\hline
\end{tabular}

\section{Inconsistências em uma única parede}

Dentre os itens relacionados no Quadro 8, algumas particularidades observadas durante sua análise contribuem para a discussão sobre a eficácia dos diferentes protótipos.

O item 8 foi detectado apenas pela prototipagem física e precisa ser melhor caracterizado. Durante o trabalho de classificação das inconsistências, observou-se que, de fato, as caixas 4x2' possuíam profundidade menor do que a soma da alvenaria e uma das camadas do reboco, o que geometricamente permitia sua instalação. Porém, ao realizar o trabalho de "rasgar a alvenaria" de $9 \mathrm{~cm}$ para instalação dessas caixas, o furo atravessa completamente a parede, atingindo o outro ambiente. 
Essa interferência não foi identificada no protótipo analítico 3D, pois parametricamente não havia qualquer interferência prevista. Assim, se o recobrimento mínimo de alvenaria para os fundos das caixas for considerado uma necessidade construtiva, faz-se necessário considerar essa condição na modelagem do compoente "caixa”, o que não ocorreu. Dessa forma, fica evidente que o grau de maturidade da modelagem precisa ser ajustado à cultura e à técnica construtiva em uso.

Outro caso semelhante ao item 8 é a inconsistência indicada no item 1, em que a detecção da necessidade de elevar a alvenaria até o fundo da laje em ambientes como banheiro ou cozinha se deve mais à experiência profissional envolvida do que pela análise por intermédio da prototipagem. Mesmo o protótipo físico não contava com qualquer procedimento de medição de desempenho que permitisse a detecção de falhas na incolumidade dos ambientes, cabendo à percepção dos profissionais envolvidos reconhecerem a inconsistência.

Em contrapartida, o item 9 demonstra uma inconsistência provocada por uma falha na leitura do projeto. Essa inabilidade profissional, porém, possui um atenuante que deve ser considerado, pois se deve, em parte, à fragmentação das informações contidas no projeto elétrico (FERREIRA, 2007). Na incompatibilidade apontada no item 9, a altura da tomada especificada na planta de indicação de iluminação e tomadas do projeto elétrico coincide com a rodabanca da bancada da cozinha. Como estão exemplificadas pelos recortes da prancha do projeto elétrico, apresentados na Figura 7, as tomadas foram indicadas em planta por simbologia padrão e esses símbolos foram apresentados na legenda referente à planta, indicando tipo, altura e demais especificações técnicas.

Observando ainda a Figura 7, nota-se um retângulo tracejado na cor azul contornando a área da bancada da cozinha. Esse tracejado não possui qualquer referência textual no desenho, mas é descrito na legenda de simbolos da seguinte forma: "as tomadas da bancada da pia da cozinha, com simbologia 1,10 m deverão estar a 1,20 m de altura”. Porém, na mesma prancha existe um detalhe em corte, que contradiz essa informação, indicando altura da caixa a 1,10 m e orientada horizontalmente.

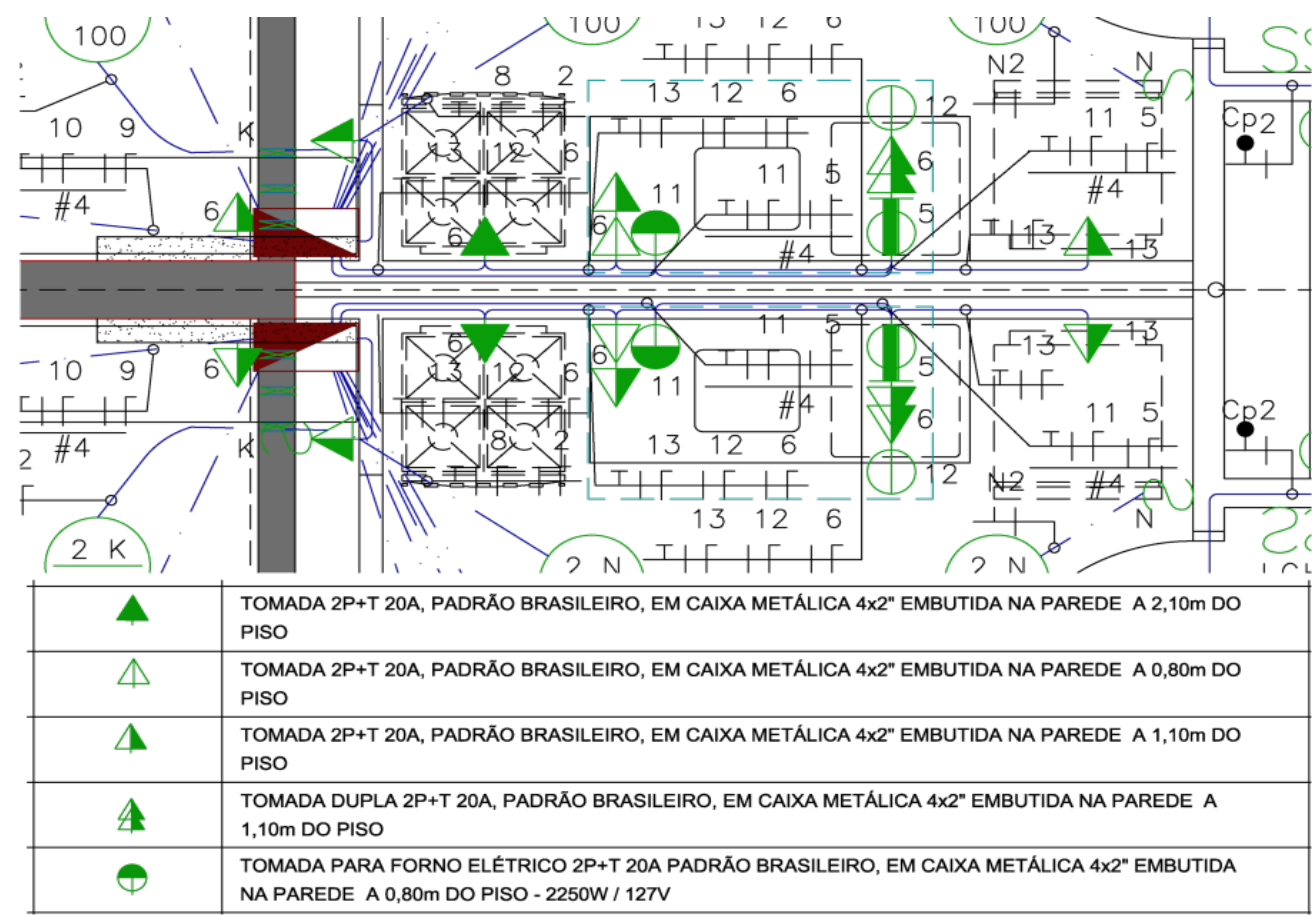

Figura 7. Recorte de planta e legenda do projeto elétrico. 
Esse detalhe em corte não estava indicado na planta ou em qualquer outro desenho da prancha. De fato, se por um lado os profissionais responsáveis pela prototipagem se ativeram apenas às informações padrão explícitas na descrição da simbologia nas pranchas, sem observar o significado da projeção azul ou as informações presentes no detalhe genérico, por outro, os profissionais responsáveis pela prototipagem analítica 3D observaram apenas o detalhe, resultando na detecção da inconsistência, conforme demonstra a Figura 8.

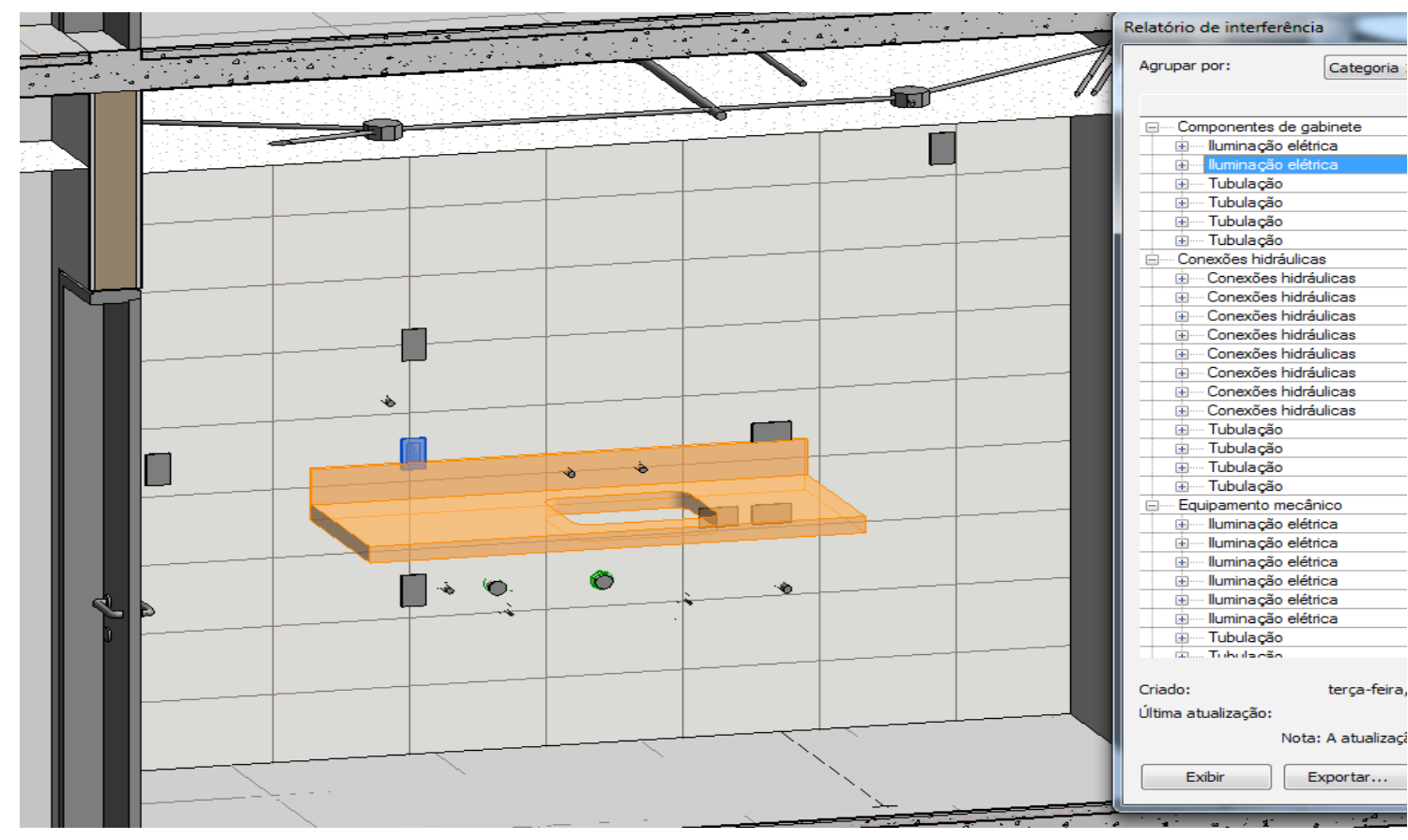

Figura 8. Não-conformidade na bancada da cozinha identificada com auxilio de um relatório de interferência do software.
Já a equipe responsável pelo protótipo analítico 2D sequer observou a incompatibilidade. Nesse caso, a dubiedade das informações prejudicou a análise de todos os envolvidos, forçando a improvisação de uma solução nova. Uma análise atenta ao registro da prototipagem física, comparando-o às demais figuras que representam o projeto, mostra que as informações de projeto foram abandonadas e redefinidas em obra. Todas as tomadas estão dispostas na vertical e, além disso, do lado esquerdo da bancada, duas dessas tomadas foram locadas sobre a bancada e uma sob ela, quando o especificado era justamente o contrário.

Essa inconsistência é agravada se for considerada uma situação sem qualquer prototipagem física, em que nenhuma solução alternativa seria adotada. Nessa situação, a bancada seria executada após conclusão do acabamento da parede com revestimentos cerâmicos, incluindo fixação das tomadas. Ou seja, o impacto de um eventual retrabalho decorrente da não detecção dessa incompatibilidade seria consideravelmente alto, uma vez que envolvolvia frentes de trabalho iniciadas há quatro meses, ou seja, havia a replicação de uma não conformidade da obra decorrente da inconsistência do projeto.

\section{CONCLUSÕES}

O estudo exploratório que resultou nesse artigo delineou um entendimento experienciado da prototipagem analítica virtual. Descontados os itens detectados na análise de compatibilização, que deveriam estar sanados para os projetos liberados para a obra, a realização do protótipo 
analítico 3D significa a deteç̧ão de $77,78 \%$ dos itens encontrados como resultado do protótipo físico. Esse valor considerável valida as vantagens de realização da modelagem de protótipos virtuais como um meio de antecipação na detecção de inconformidades.

Das detecções consideradas, foi demonstrada a possibilidade de antecipação de $40 \%$ dos problemas identificados no protótipo físico ainda na etapa de projeto, apenas analisando os projetos executivos liberados para obra. Isso significa que essas inconsistências poderiam ser mitigadas caso os desenhos técnicos, além de um instrumento de comunicação documental das definições do projeto, fossem encarados como uma oportunidade de prototipagem analítica 2D. Isso acarretaria, no entanto, um volume ainda maior de trabalho.

Porém, cabe ressaltar que a prática da prototipagem analítica 2D, embora seja rápida e demande poucos recursos e tecnologia para sua produção, quando comparada à prototipagem física ou mesmo à prototipagem analítica 3D, apresenta limitada capacidade de integrar informações de projetos complexos, como são os projetos do ambiente construído. Questiona-se, assim, a validade dos esforços empregados em insistir em práticas desse tipo de prototipagem.

Diante dessa perspectiva, a prototipagem analítica 3D encontra subsídio nas tecnologias BIM. Ao associar à modelagem paramétrica, tanto o gerenciamento integrado das informações do projeto como a possibilidade de avaliar o desempenho do produto, a tecnologia BIM aproxima a prototipagem analítica da prototipagem física em vários aspectos. Com maior rapidez e economia, é possível simular virtualmente parâmetros físicos do produto, planejar as etapas de execução, quantificar insumos, facilitar a orçamentação e o controle de recursos e avaliar com mais precisão a qualidade do ambiente.

Os resultados apresentados no estudo de caso permitiram comparar o desempenho da prototipagem física e analítica 3D realizadas durante o início da construção da edificação com o objetivo de identificar as inconsistências de projeto. Se por um lado, a validade dessa comparação restrita ao apartamento tipo pode ser questionada, diante da maior complexidade observada em outras partes do edifício por exemplo, o térreo, a casa de máquinas ou os subsolos, cabe observar que esse recorte se deve às limitações da prototipagem física em um produto único.

A bibliografia aponta que os benefícios da prototipagem analítica 3D poderiam ser maiores se a mesma fosse incorporada desde as fases iniciais do PDP do ambiente construído. A comparação relatada nesse artigo reforça esse entendimento, pois, embora tenha apontado para maior capacidade de detecção das inconsistências do projeto, as oportunidades de intervenção para solucioná-las foram limitadas. Se detectadas durante o desenvolvimento do projeto, as possibilidades de solução para eventuais inconsistências seriam maiores e os custos atrelados a ela, menores. Ao mesmo tempo, não sendo tão demandada para identificar inconsistências, a prototipagem física poderia ser melhor explorada para estudar fenômenos típicos da produção, promover treinamento de pessoal e a padronização e a melhoria da produção em situações muito complexas. Além dessas possíbilidades, outro benefício da prototipagem física é a divulgação e comercialização do produto como apartamentos decorados ou maquetes.

Com a antecipação da prototipagem analítica, incorporada à modelagem de informação da edificação, o escopo do projeto do ambiente construído aumenta consideravelmente. Em um sentido mais profundo, a responsabilidade sobre a integração das informações dos projetos, que é assumida atualmente pela produção, porque ocorre durante a construção do edifício, migra para o projeto. Esse novo paradigma, baseado na modelagem de informação, deve impactar nas relações organizacionais do setor, na forma de comunicação do projeto e até na forma como os projetistas devem pensar o produto. Assim, a oportunidade de diminuir o risco e a incerteza 
na produção se traduz em novos desafios ao desenvolvimento do projeto, promovendo a revalorização das atividades relacionadas a ele.

Barreiras culturais e organizacionais são empecilhos à integração dos diferentes processos do PDP, que envolvem viabilidade, desenvolvimento e produção. $O$ presente trabalho se concentrou na relação entre esses dois últimos, demonstrando que a prototipagem analítica 3D, possível com a modelagem paramétrica, contribui significativamente para redução de incertezas do processo. Indiretamente, impacta ainda na economia de custos e prazos, pois independe do início da execução do edificio e oferece garantias de qualidade das informações projetadas para o empreendimento.

Os resultados observados apresentaram um panorama promissor para implementação da prototipagem analítica, a partir de ferramentas BIM, como uma alternativa válida e economicamente vantajosa sobre a prototipagem física para detectar inconformidades de projeto. Porém, diante dessa constatação, novas questões se estabelecem como direcionamentos para futuras pesquisas. Elas envolvem o estudo de desenhos organizacionais que reposicionem o papel do projeto no PDP, a exploração do potencial tecnológico para realização de simulações em $n$ dimensões, identificação das dificuldades conjunturais de implementação e amadurecimento dessas tecnologias no setor e quais novas competências surgirão.

\section{REFERÊNCIAS}

ARAYICI, Y et al. BIM implementation and Adoption Process for an Architectural Practice. The School of Built Environment, the University of Salford. Greater Manchester, p. 22. 2011.

BEYNON-DAVIES, B.; TUDHOPE, D.; MACKAY, H. Information systems prototyping in practice. Journal of Information Technology, Londres, v. 14, p. 107-120, 1999.

BONSIEPE, G. Design as tool for cognitive metabolism: from knowledge production to knowledge presentation. International Symposium on the Dimensions of Industrial Design Research Ricerca+Design. Milão: Politecnica de Milão, p. 1-14, 2000

BOUCHLAGHEM, D. et al. Visualisation in architecture, engineering and construction (AEC). Automation in Construction, n. 14, p. 287-295, 2005.

BROWN, S. L.; EISENHARDT, K. M. Product development: past research, present findings and future directions. Academy of Management Review, Mississippi, MS, v. 20, n. 2, p. 343-378, 1995.

FAITHFULL, P. T.; BALL, R. J.; JONES, R. P. An investigation into the use of hardwarein-the-loop simulation with a scaled physical prototype as an aid to design. Journal of Engineering Design, v. 12, ก. 3, p. 231-243, 2001.

FERREIRA, R. C. Uso do CAD 3D na compatibilização espacial em projetos de produção de vedações verticais em edificações. 2007. Dissertação (Mestrado)
- Escola Politécnica, Universidade de São Paulo, São Paulo, 2007.

GRIMM, T. User's guide to rapid prototyping. Dearborn: Society of Manufacturing Engineers, 2004.

HOLMBERG, S. C. Design and prototyping towards anticipatory applications. In: INTERNATIONAL CONFERENCE OF COMPUTING ANTICIPATORY SYSTEMS, 3, 1999, Oslo. Proceedings... Oslo, 2000. 11 p.

INCUBADORA DE EMPRESAS DA UNIVERSIDADE ESTADUAL DO CEARÁ. Aprenda a calcular o preço certo dos seus produtos. Disponivel em: <http://www. uece.br/incubauece/index.php/noticias/14lista-de-noticias/243-aprenda-a-calcularo-preco-certo-dos-seus-produtos>. Acesso em: 24 mar.2015

KALAY, Y. E. The impact of information technology on design methods, products and practices. Design Studies, Elsevier, v. 27, p. 357-380, maio 2006.

KIVINIEMI, A.; FISHER, M. Potential Obstacles to Use BIM in Architectural Design. In: SHEN, G. Q.; BRANDON, P.; BALDWIN, A. (Eds.). Collaborative Construction Information Management. Oxon: Spon Press, 2009. p. 36-54.

PATTERSON, M. L. Leading product innovation: accelerating growth in a product-based business. Nova York: John Wiley \& Sons, 1999.

REINERTSEN, D. Managing the design factory: a product developer's toolkit. Nova York: Free Press, 1997. 280 p. 
ROSENTHAL, S. R.; TATIKONDA, M. V. Competitive advantage through design tools and practices. In: SUSMAN, G. I. (Ed.). Integrating design and manufacturing for competitive advantage. Londres: Oxford University Press, 1992. 320p.

SEBRAE. Como calcular a margem de lucro de um produto. Portal Tributário. Abr. 2012. Disponivel em: <http://www. boletimdoempreendedor.com.br/boletim. aspx\%3FcodBoletim\%3D478>. Acessado em 24 mar. 2015.

SMITH, P.; REINERTSEN, D. Developing Products in Half the Time: New Rules, New Tools. 2. ed. [S.I.]: [s.n.], 1997.
SUCCAR, B. Building information modelling framework: A research and delivery foundation for industry stakeholders. Automation in Construction, v. 18, p. 357-375, out. 2009. Disponível em: www. elsevier.com/locate/autcon.

TSE, K. T.; WONG, K. A.; WONG, K. F. The utilisation of building information models in $\mathrm{nD}$ modelling: a study of data interfacing and adoption barriers. ITcon, v. 10, p. 85-110, 2005.

ULRICHI, K. T.; EPPINGER, S. D. Product design and development. 5 ed. Massachusetts: Mc Graw Hill, 2011. 432 p.
Lucas Melchiori Pereira Ic.melchiori@gmail.com

Fernanda Aranha Saffaro saffaro@uel.br

Ercilia Hitomi Hirota erciliahh@gmail.com

Celso Saito

celsosaito@hotmail.com 